\title{
RHINOLOGY
}

\section{The SWI/SNF complex in eosinophilic and non eosinophilic chronic rhinosinusitis}

\author{
II complesso SWI/SNF nella rinosinusite cronica eosinofila e non eosinofila

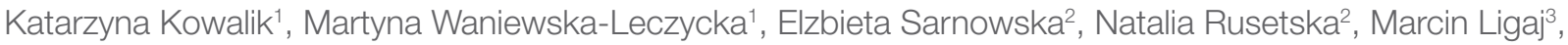 \\ Alicja Chrzan ${ }^{3}$, Mariola Popko ${ }^{1}$ \\ ${ }^{1}$ Department of Otorhinolaryngology, Faculty of Medicine and Dentistry, Medical University of Warsaw, Warsaw, Poland; \\ ${ }^{2}$ Department of Molecular and Translational Oncology, Maria Sklodowska-Curie National Research Institute of Oncology, Warsaw, \\ Poland; ${ }^{3}$ Department of Pathology, Maria Sklodowska-Curie National Research Institute of Oncology, Warsaw, Poland
}

\section{SUMMARY}

Introduction. Chronic rhinosinusitis (CRS) can be classified as eosinophilic (eCRS) or non-eosinophilic (neCRS) based on infiltration type. The SWI/SNF complex may be involved in the pathophysiology of CRS.

Aim. To assess the expression of the SWI/SNF complex in both CRS groups; to correlate blood eosinophil count (BEC), and histopathology eosinophil count (HPEC) with the SWI/ SNF expression level in eCRS and neCRS.

Materials and methods. The study population consisted of 96 patients (68 eCRS, 28 neCRS). Immunohistochemical staining was performed on sinonasal mucosa for assessment of SWI/SNF protein expression. Type of tissue infiltration was assessed in samples obtained from examined groups (HPEC). The diagnostic value of eCRS was 10 cells/HPF (high power field). Complete blood count was analysed in order to calculate BEC.

Results. BEC and HPEC correlated negatively with all the SWI/SNF subunits. HPEC and BEC correlated positively with clinical findings (L-M and SNOT-22), while SWI/SNF correlated negatively with clinical findings (L-M and SNOT-22).

Conclusions. The SWI/SNF was observed in both eCRS and neCRS, with lower expression in former. The meaning of its negative correlation with BEC, HPEC and clinical findings in eCRS group remains to be understood.

KEY WORDS: SWI/SNF, sinusitis, eosinophils, eCRS

\section{RIASSUNTO}

Introduzione. La rinosinusite cronica (CRS) può essere classificata come eosinofila (eCRS) o non-eosinofila (neCRS), in base al tipo di infiltrato cellulare. Il complesso SWI/SNF potrebbe avere un ruolo nella fisiopatologia della CRS.

Obiettivo. Valutare l'espressione del complesso SWI/SNF in entrambi i gruppi di CRS; correlare la conta degli eosinofili nel sangue $(B E C)$ e la conta degli eosinofili nel preparato istopatologico (HPEC) con il livello di espressione SWI/SNF nei gruppi eCRS e neCRS. Materiali e metodi. La popolazione dello studio è composta da 96 pazienti (68-eCRS, 28-neCRS), è stata eseguita la colorazione immunoistochimica sulla mucosa rinosinusale per valutare i livelli di espressione della proteina SWI/SNF, è stato valutato il tipo di infiltrato cellulare nei campioni ottenuti (HPEC). Valore di eosinofili, diagnostico di eCRS: 10 cellule / HPF. È stato analizzato l'emocromo completo per calcolare il BEC.

Risultati. BEC e HPEC sono risultati inversamente correlati con tutte le subunità SWI/ SNF e correlati positivamente con i dati clinici (L-M e SNOT-22), mentre SWI/SNF erano correlati negativamente con i risultati clinici ( $L-M$ e SNOT-22).

Conclusioni. Il complesso SWI/SNF è risultato presente sia in eCRS che in neCRS, con un'espressione inferiore nel primo tipo di rinosinusite cronica. Il significato della sua correlazione negativa con BEC, HPEC e risultati clinici nel gruppo eCRS resta da indagare.

PAROLE CHIAVE: SWI/SNF, sinusite, eosinofili, eCRS
Received: March 23, 2020

Accepted: November 9, 2020

\section{Correspondence}

Mariola Popko

Department of Otorhinolaryngology, Faculty of Medicine and Dentistry, Medical University of Warsaw, Stepinska 19/25. 00-739 Warsaw, Poland Tel. +48 694012224. Fax +48223186266 E-mail: popkom@interia.pl

Funding

None.

Conflict of interest

The Authors declare no conflict of interest.

How to cite this article: Kowalik K, Waniewska-Leczycka M, Sarnowska E, et al. The SWI/ SNF complex in eosinophilic and non eosinophilic chronic rhinosinusitis. Acta Otorhinolaryngol Ital 2021;41:159-167. https://doi. org/10.14639/0392-100X-N0760

() Società Italiana di Otorinolaringoiatria e Chirurgia Cervico-Facciale

\section{(c) (1) $(2)$}

This is an open access article distributed in accordance with the CC-BY-NC-ND (Creative Commons Attribution-NonCommercial-NoDerivatives 4.0 International) license. The article can be used by giving appropriate credit and mentioning the license, but only for non-commercial purposes and only in the original version. For further information: https:// creativecommons.org/licenses/by-nc-nd/4.0/deed.en 


\section{Introduction}

Chronic rhinosinusitis (CRS) is a multifactorial inflammatory disease of the nasal and paranasal mucosa. CRS patients often experience altered innate immune response in the mucosa and a tendency towards infection by pathogenic microorganisms. Until the publication of European Position Paper on Rhinosinusitis and Nasal Polyps in 2020 (EPOS 2020), CRS was categorised based on disease phenotype, i.e. presence or absence of nasal polyps (chronic rhinosinusitis with (CRSwNP) or without nasal polyps (CRSsNP). This classification did not inform about differences in pathophysiology and which cells of the immune system played the biggest role in the inflammation mechanisms ${ }^{1-3}$. CRS pathophysiology is multifactorial, including fungi, bacteria, viruses, biofilm, microbiome variability and superantigens which may activate the immune system ${ }^{4,5}$. One interesting mechanism is the impact of pathogens on $\mathrm{T}$ helper lymphocytes and their activation of the different specialised stages as Th1, Th2 and Th17. Furthermore, lymphocytes produce cytokines and affect other immune cells like eosinophils (Th2) and neutrophils (Th1, Th17). Therefore, given that various inflammatory mediators and cells are triggered by and influence the course of the disease, further subclassification of CRS was proposed based on cytokines and other inflammatory mediators that may be more important to the mechanisms of the disease ${ }^{1,5}$. The endotypes of CRS according to the EPOS 2020 are divided into type 2 of immune response with Th2 lymphocytes and Type non-type 2 with Th1 or Th17 lymphocytes. Further, CRS can be subclassified as either eosinophilic CRS (eCRS) or non-eosinophilic CRS (neCRS), based on predominant inflammatory cell type that modulates mucosal immunity ${ }^{1}$.

The histopathological type of CRS may vary depending on race. Asian populations tend to experience significant mucosal neutrophilia and associated neutrophilic inflammation, while Caucasian populations exhibit abundant tissue eosinophilia and eosinophilic inflammation in CRS ${ }^{1}$. Moreover, eosinophilic CRS often coexists with asthma and aspirin hypersensitivity. These patients are often recalcitrant and non-responding to CRS therapy and sinus inflammation frequently recurs after surgery ${ }^{6,7}$. Activated eosinophils in the sinonasal mucosa are reported to play a role in the inflammatory process through cationic proteins with the release of granule proteins ${ }^{1}$. In our previous study, we showed that lower expression of BRG1 in CRS correlates with higher levels of blood eosinophils. This negative correlation of the SWI/SNF complex with eosinophils may expound the worse prognosis in this group of patients with eCRS ${ }^{8}$.
The chromatin remodelling in the SWI/SNF complex is involved in transcriptional control, DNA repair, hormonal signalling and inflammation ${ }^{9}$. Moreover, the SWI/SNF complex may play a role in the development and treatment of CRS, since it regulates glucocorticoid receptors (GCs), which determine the regulation of glucocorticoiddependent gene expression ${ }^{10,11}$. The SWI/SNF also regulates the action of vitamin D, and in CRS patients, SWI/ SNF expression correlates with expression of the vitamin D receptor $(\mathrm{VDR})^{8}$. In addition, the combination of activated VDR and the SWI/SNF complex is able to promote antiinflammatory processes ${ }^{12}$. Vitamin $\mathrm{D}$ and its receptors may play a crucial role in regulating immune mucosal function in CRS ${ }^{1}$. This association of the SWI/SNF with GCs and vitamin $\mathrm{D}$ may contribute to the pathogenesis of CRS as reflected in the abundance of the SWI/SNF complex ${ }^{8,10,12}$. The mechanisms underlying eosinophilic inflammation in CRS are still largely unknown, and as such, the relationship between CRS and the SWI/SNF must be further analysed. The aims of this study were: 1 . to assess expression of the SWI/SNF complex in both eCRS and neCRS patient groups; 2. to assess correlations between blood eosinophil count (BEC) or histopathological eosinophil count (HPEC) and SWI/SNF expression levels in eCRS and neCRS.

\section{Materials and methods}

\section{Study design and population}

The study population consisted of 96 CRS patients (42 with CRSsNP and 54 with CRSwNP), all of whom had undergone endoscopic sinus surgery between July 2015 and February 2017 at the Department of Otorhinolaryngology, Faculty of Medicine and Dentistry, at the Medical University of Warsaw. The current study group derives from the same population of CRS patients we analysed in a previous study. Patients were analysed according to the new EPOS guidelines and extrapolated. All patients had first undergone a three-month course of conservative therapy (Adequate Medical Therapy, or AMT) ${ }^{1}$. If AMT was unsuccessful, patients then qualified for surgical treatment. The study group was designed based on the criteria of the EPOS, and underwent an interview, physical examination including endoscopic examination of the nasal cavities and computed tomography (CT) scan of the paranasal sinuses ${ }^{1}$. Exclusion criteria were: unilateral CRS or nasal polyps, antrochoanal polyps, inverted papilloma, nasal or paranasal malignancy, allergic fungal rhinosinusitis, systemic disease (such as sarcoidosis, autoimmune disease, or cystic fibrosis) and women who may be pregnant.

Patients completed a Sino-Nasal Outcome Test (SNOT-22) questionnaire for the evaluation of sinus complaints ${ }^{1}$ and 
disease severity was categorised using CT scans, according to the Lund-Mackay scoring system ${ }^{13}$. During ENT examination, patients were assessed endoscopically according to the Lund-Kennedy (L-K) scale ${ }^{14}$. None of the patients was treated with antibiotics, systemic or topical corticosteroids, or other immune-modulating drugs for at least one month before surgery. Aspirin intolerance was defined as the exacerbation of nasal symptoms triggered by aspirin or nonsteroidal anti-inflammatory drug (NSAID) exposure ${ }^{15}$. Data on allergy status were collected in medical interviews, and confirmed with skin prick tests and by assessing total immunoglobulin E (IgE) levels in blood. Bronchial asthma was determined according to GINA 2015 criteria ${ }^{16}$. Complete blood count was analysed to calculate blood cell counts, especially eosinophil counts, for both groups (ALAB laboratory).

The study was conducted in accordance with the ethical standards of the Local Ethics Committees of Warsaw Medical University in Poland, No. KB/209/2016, and with the Helsinki Declaration. All participants provided informed written consent.

\section{Immunohistochemical staining}

Sinonasal mucosa were surgically removed from the osteomeatal complex and examined by immunohistochemistry. Samples were fixed in $10 \%$ formalin solution and embedded in paraffin. Staining was performed on $3.5 \mu \mathrm{m}$ sections of tissue sheared from the paraffin blocks. Immunohistochemistry was performed using the method detailed in our previous study ${ }^{17}$. The sections were treated with optimal antibody dilutions: anti-SMARCC1/BAF-155 (1:200 for 1 hour at $25^{\circ} \mathrm{C}$ ) monoclonal antibodies (D7F8S) (Cell Signalling Technology), BRG1 (1:100 for 12 hours at $\left.5^{\circ} \mathrm{C}\right)(\mathrm{G}-7)$ (Santa Cruz Biotechnology), and BRM (1:200 for 1 hour at $25^{\circ} \mathrm{C}$ ) (D9E8B) XP (Santa Cruz Biotechnology) subunits of the chromatin remodelling complex the SWI/SNF type. Colour was developed using 3.3'-diaminobenzidine tetrahydrochloride (Dako). Haematoxylin staining was performed for $1 \mathrm{~min}$ and sections were embedded in balsam. Protein expression levels for each the SWI/SNF subunit were analysed by light microscopy and based on the Hscore system.

\section{Quantification of eosinophils in tissue samples}

To evaluate the degree of cell infiltration, we used quantification techniques described by Bhattacharyya et al. to count the number of eosinophils determined by haematoxylin and eosin (H\&E) staining ${ }^{18}$. First, we performed a low-power survey of each slide at x20 and x100 magnification to identify sinus mucosa. Polyps and mucosa with glandular elements were excluded. Next, we identified the mucosal tissue with the highest degree of eosinophilic infiltration and examined those samples under $\times 400$ magnification with a $10 \times 10 \mathrm{~mm}$ reticulate in the eyepiece. The total number of eosinophils was determined as the count per high-power field (HPF). Eosinophilic polyps were defined as those where the eosinophil count was more than 10 cells/HPF; non-eosinophilic polyps were defined as those where the eosinophil count was less than 10 cells/HPF ${ }^{1,6}$.

\section{Statistical analysis}

The results were subjected to statistical analysis using Statistica 13.1. Normality distribution and uniformity of valence were determined. Basic statistics were analysed due to the antibodies being evaluated. A Mann-Whitney U test and chi-square test were used to determine whether the differences between groups were significant. A Spearman test was used to analyse correlations between variables in the groups and protein expression levels of the SWI/SNF complex. Differences were considered to be significant when $\mathrm{p}<0.05^{19}$.

\section{Results}

Clinical characteristics of the study groups

Forty-two patients with CRSsNP and 54 patients with CRSwNP were enrolled in the study (a total of 96 CRS patients) (Tab. I). Participants were categorised as either eCRS or neCRS based on routine histopathology examination of H\&E specimens. The eCRS group consisted of 68 patients (42 males and 26 females, ranging in age from 18 to 83 and with a mean age of 48.8 years). The neCRS group constituted of 28 patients (18 males and 10 females, ranging in age from 18 to 81 and with a mean age of 41.7 years). In the CRSwNP group ( $\mathrm{n}=54)$, seven patients had neCRS and 47 had eCRS. In the CRSsNP group $(n=42)$, 21 patients had neCRS and 21 had eCRS. Patients with eCRS accounted for $87 \%$ of the CRSwNP group $(n=47)$ and $50 \%$ of the CRSsNP group $(\mathrm{n}=21)$. The distribution of the CRSsNP and CRSwNP patients was different between eCRS and neCRS groups and influenced the clinical features of patients. Patient characteristics are presented in Table I. We found no differences in age and sex between groups $(p>0.05)$. Patients in the eCRS group presented with a significantly higher incidence of asthma, allergies and Lund-Mackay CT scores or Lund-Kennedy scores compared with neCRS patients $(\mathrm{p}<0.05)$. We observed differences in subjects with aspirin-exacerbated respiratory disease (AERD) and in SNOT-22 results when comparing eCRS and neCRS groups, but these were not statistically significant $(\mathrm{p}>0.05)$. 
Table I. Clinicopathological characteristics of CRS patients.

\begin{tabular}{|c|c|c|c|c|c|c|}
\hline Group & $\begin{array}{l}\text { CRSsNP } \\
(n=42)\end{array}$ & $\begin{array}{l}\text { CRSwNP } \\
(n=54)\end{array}$ & $p$-value & $\begin{array}{c}\text { eCRS } \\
(n=68) \\
(47 \text { CRSwNP; } 21 \text { CRSsNP) }\end{array}$ & $\begin{array}{c}\text { neCRS } \\
(n=28) \\
\text { (7 CRSwNP; } 21 \text { CRSsNP) }\end{array}$ & $\mathrm{p}$-value \\
\hline Age range & $18-77$ & $22-83$ & 0.66 & $18-83$ & $18-81$ & 0.68 \\
\hline \multicolumn{7}{|l|}{ Sex } \\
\hline$M$ & 25 & 35 & 0.7 & 42 & 18 & 0.85 \\
\hline Allergy & 16 & 23 & 0.66 & 30 & 9 & 0.04 \\
\hline AERD & 0 & 6 & $<0.03$ & 4 & 2 & 0.07 \\
\hline SNOT-22 score & 34.2 & 38.2 & 0.29 & 36.1 & 35.7 & 0.78 \\
\hline Lund-Kennedy score & 5.1 & 8.7 & $<0.001$ & 7.7 & 5.5 & 0.001 \\
\hline HPEC (cells/HPF) range & $0-550$ & $2-405$ & $<0.01$ & $10-550$ & $0-9$ & \\
\hline Average & 66.8 & 97.7 & & 117.4 & 3.4 & \\
\hline
\end{tabular}

CRSSNP: patients with chronic rhinosinusitis without nasal polyps; CRSWNP: patients with chronic rhinosinusitis with nasal polyps; eCRS: patients with eosinophilic chronic rhinosinusitis; neCRS: patients with non-eosinophilic chronic rhinosinusitis; M: male; F: female; AERD: aspirin-exacerbated respiratory disease; BEC: blood eosinophil count; HPEC: histopathological eosinophil count.

\section{Eosinophils in blood and tissue}

The type of tissue infiltration was assessed using histopathology samples obtained from both examined groups (Fig. 1). Eosinophilic infiltration was defined by an eosinophil count of more than 10 cells/HPF for the eCRS group and fewer than 10 cells/HPF for the neCRS group (Fig. 1). Patients in the eCRS group exhibited higher histopathology eosinophil counts (HPEC) (mean 117.4 cells/ HPF, range 10-550 cells/HPF) than those in the neCRS group (mean 3.4 cells/HPF, range $0-9$ cells/HPF). The differences between the two groups were statistically significant $(\mathrm{p}<0.001)$ (Fig. 2A).

Furthermore, significant differences were observed when measuring blood eosinophil count (BEC) for both the eCRS and neCRS groups $(\mathrm{p}<0.004)$. Subjects in the eCRS group exhibited higher BEC than those in the neCRS group (Fig. 2B). The mean BEC was 0.41 cells $/ \mu \mathrm{L}$ for eCRS patients and 0.15 cells/ $\mu \mathrm{L}$ for neCRS patients (Tab. I). Statistical analysis showed that the differences between groups were significant. Furthermore, there was a strong positive correlation between BEC and HPEC $(\mathrm{r}=0.59 ; \mathrm{p}=0.000)$ (Fig. 2C).

The analysis of the other clinical data showed that histopathological eosinophil count (HPEC) correlated positively with Lund-Mackay CT score $(r=0.32 ; p=0.01)$ (Fig. $3 \mathrm{~A})$. The other indicator of the CRS severity is SNOT-22, and we observed that blood eosinophil count (BEC) cor- relates positively with SNOT-22 $(\mathrm{r}=0.31 ; \mathrm{p}=0.026)$, and Lund-Mackay CT scores $(r=0.43 ; p=0.0001)$ (Fig. 3B).

\section{SWI/SNF protein expression levels in CRS}

In both groups, SWI/SNF expression was confirmed. Mucosal nuclear staining results are presented in Figure 4A. In the eCRS group, we observed a significant correlation between BEC and the SWI/SNF subunits. Figure 4B presents the negative correlation between BEC and BRM protein expression levels $(r=-0.34$; $\mathrm{p}=0.04)$, BRG 1 protein expression levels $(\mathrm{r}=-0.45$; $\mathrm{p}=0.006)$ and BAF 155 protein expression levels $(\mathrm{r}=-0.43 ; \mathrm{p}=0.01)$. Furthermore, significant correlations between HPEC and the SWI/SNF subunits were observed in eCRS patients. Figure 4C shows the correlation between HPEC and BRM protein expression levels $(\mathrm{r}=-0.40 ; \mathrm{p}=0.015)$, BRG 1 protein expression levels $(\mathrm{r}=-0.34 ; \mathrm{p}=0.045)$ and BAF 155 protein expression level $(\mathrm{r}=-0.32 ; \mathrm{p}=0.01)$.

The SWI/SNF subunits correlated negatively with clinical findings. Expression of BRM $(r=-0.26 ; p=0.03)$ and BAF $155(r=-0.35 ; p=0.004)$ correlated negatively with L-M CT scores (Fig. 5A). Moreover, all examined subunits (BRM: $\mathrm{r}=-0.25 ; \mathrm{p}=0.05, \mathrm{BRG} 1: \mathrm{r}=-0.26 ; \mathrm{p}=0.04$, BAF 155: $r=-0.26 ; p=0.04)$ correlated negatively with SNOT-22 (Fig. 5B). 


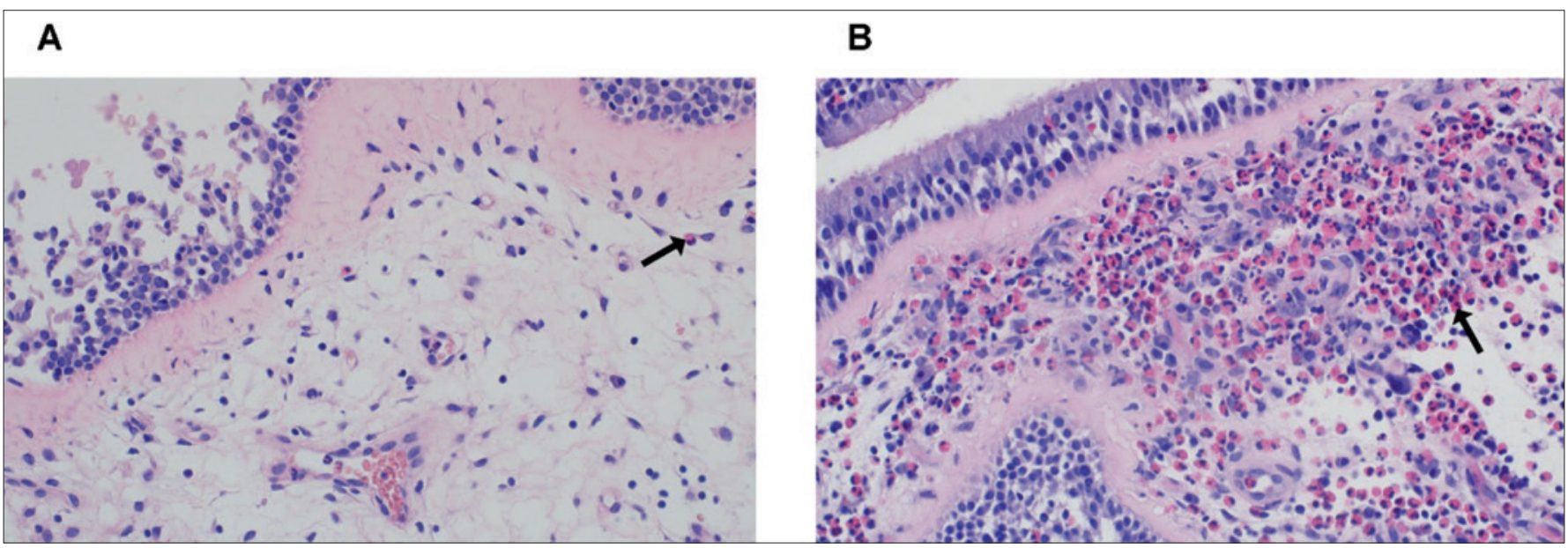

Figure 1. Eosinophilic infiltration of CRS tissue in histopathology samples. (A) Non-eosinophilic chronic rhinosinusitis (neCRS, $<10$ eos/HPF) (p < 0.05). (B) E0sinophilic chronic rhinosinusitis (eCRS, > 10 eos/HPF). Magnification: 400x. Arrows indicate the position of eosinophils.

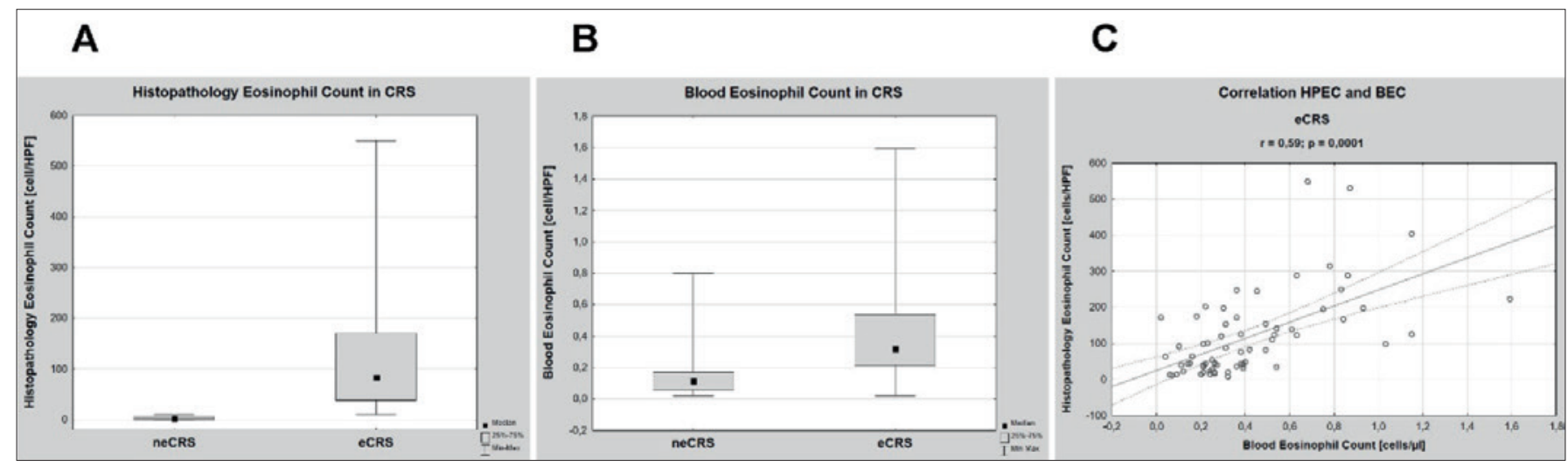

Figure 2. Eosinophils in blood and tissue of patients with chronic rhinosinusitis (CRS). (A) Higher histopathological eosinophil counts (HPEC) in patients with eosinophilic chronic rhinosinusitis (eCRS) than in patients with non-eosinophilic chronic rhinosinusitis (neCRS) $(p<0.05)$. (B) Higher blood eosinophil counts (BEC) in patients with eCRS than in patients with neCRS $(p<0.05)$. (C) Correlation between BEC and HPEC in patients with eCRS. In this group, BEC and HPEC presented a positive correlation $(\mathrm{p}<0.05)$.

\section{Discussion}

Recent publications have sought to better understand the pathophysiology of CRS, and the division of CRS patients into groups by eosinophilic or non-eosinophilic inflammation reflects this tendency. While eCRS is histologically characterised by notable levels of eosinophil infiltration of sinonasal tissue, it has been suggested that the degree of eosinophilic inflammation is also associated with the clinical manifestation and recurrence of the disease, as well as greater symptomatology and higher rates of CRS treatment failure ${ }^{1,20,21}$. Our study makes an important contribution to studying the pathophysiology of CRS. Our main findings are: expression of SWI/SNF occurs in the sinonasal mucosa of both CRS groups, blood eosinophil count (BEC) correlates negatively with all SWI/SNF subunits that were studied (BRM, BRG1, and BAF155), histopathology eosinophil count (HPEC) correlates negatively with the SWI/ SNF subunits, HPEC and BEC correlate positively with clinical findings (L-M CT scores and SNOT-22) and SWI/ SNF correlates negatively with clinical findings (L-M CT scores and SNOT-22).

Worse prognoses and more frequent relapse characterise eCRS ${ }^{1}$, and Fokkens et al. have proposed alternate ways for patients to manage the disease ${ }^{1}$. The inflammatory mechanisms and molecular processes for eCRS are still being analysed, and only recently was a relationship between eosinophils and the SWI/SNF chromatin remodelling complex documented ${ }^{8}$. The SWI/SNF subunits are engaged in controlling transcription, hormonal signalling, DNA repair and inflammatory processes ${ }^{9}$, but the complex itself also regulates $\mathrm{GC}$ receptors and vitamin $\mathrm{D}$ function ${ }^{10,12}$. The 


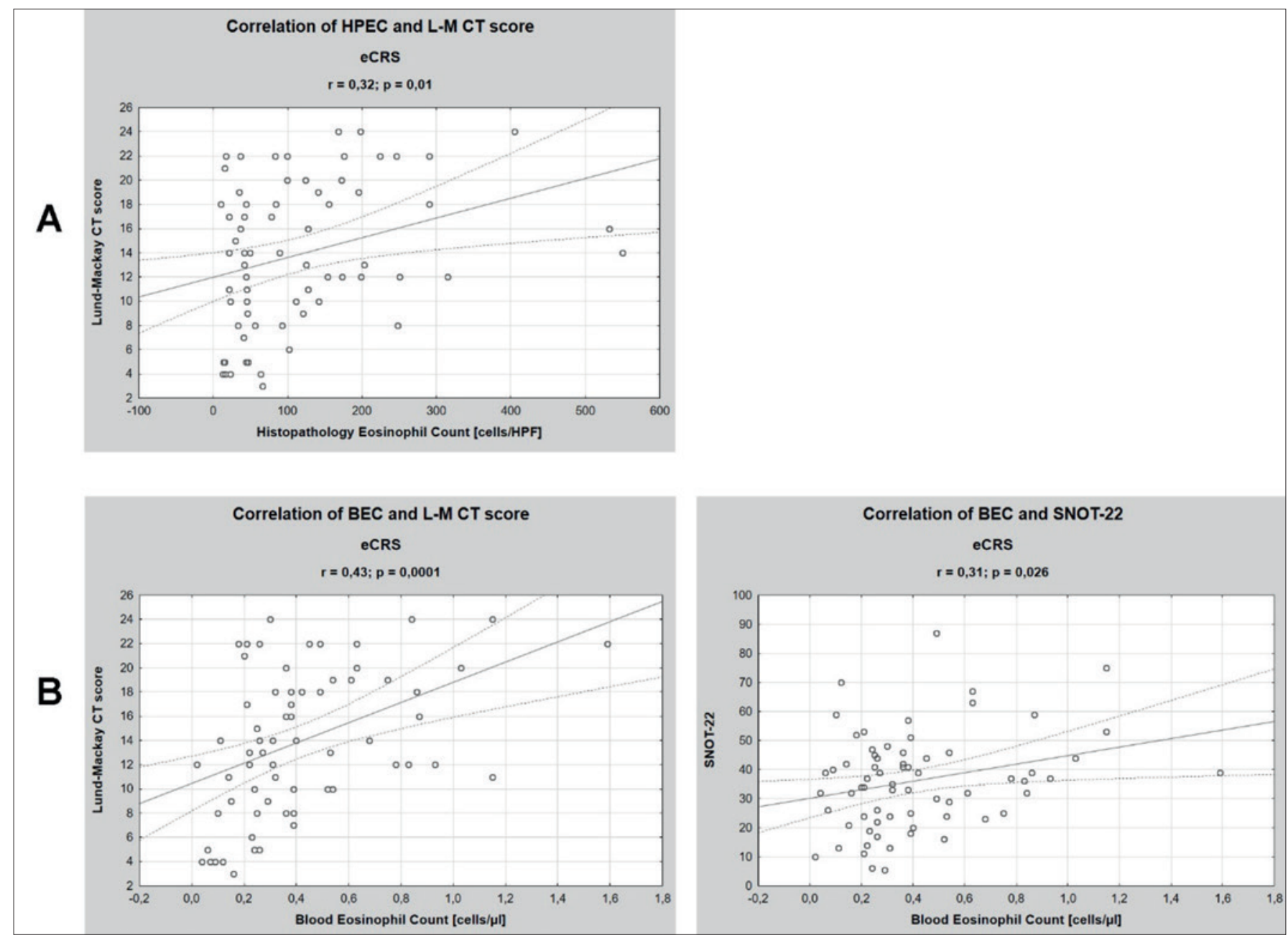

Figure 3. The Spearman correlation for histopathology eosinophil count (HPEC) and clinical findings. (A) Correlation between HPEC and Lund-Mackay (L-M) CT scores in patients with eosinophilic chronic rhinosinusitis (eCRS). In this group, HPEC presented a positive correlation with L-M CT scores ( $p<0.05)$. (B) Correlation between blood eosinophil count (BEC) and L-M CT scores/SNOT-22 in patients with eCRS. In this group, BEC correlated positively with both L-M CT scores and SNOT-22 $(p<0.05)$.

subunits of the chromatin SWI/SNF remodelling complex interact directly with the glucocorticoid receptor (GR) and regulate the expression of the GC response genes through binding to repeating DNA sequences called hormonal response elements (HREs) ${ }^{10,11}$. Therefore, proper GR function is dependent on the SWI/SNF complex, which determines the regulation of glucocorticoid-dependent gene expression. The latest studies indicate that the SWI/SNF complex is able to promote anti-inflammatory processes ${ }^{12}$ and, as such, the SWI/SNF complex may also be involved in the pathophysiology of CRS. In this study, we demonstrated that protein expression of the SWI/SNF occurs in the sinonasal mucosa of eCRS and neCRS patients.

We also found a negative correlation between the SWI/SNF subunits with blood and histopathology eosinophil count (BEC and HPEC). Patients with high BEC presented lower levels of BRM, BRG1 and BAF155 protein expression, while patients with high HPEC had lower expression of all the SWI/SNF subunits examined. This might be because impaired SWI/SNF expression influences the inflammatory processes in eCRS and creates resistance to GC treatment. There is evidence that the SWI/SNF complex is involved in GC function and that it may control inflammatory processes through macrophages that influence the expression of many important cytokines, e.g., IL-6 ${ }^{10-12,22}$.

When diagnosing CRS, it is also important to determine disease stage. The severity of general CRS symptoms can be estimated using a variety of tools. One is by using CT scans of the paranasal sinuses to assess gradation of shadowing. The Lund-Mackay CT score is a widely used method for radiologic staging of CRS ${ }^{13}$. Despite its simplicity, it correlates well with disease severity and enables medical 


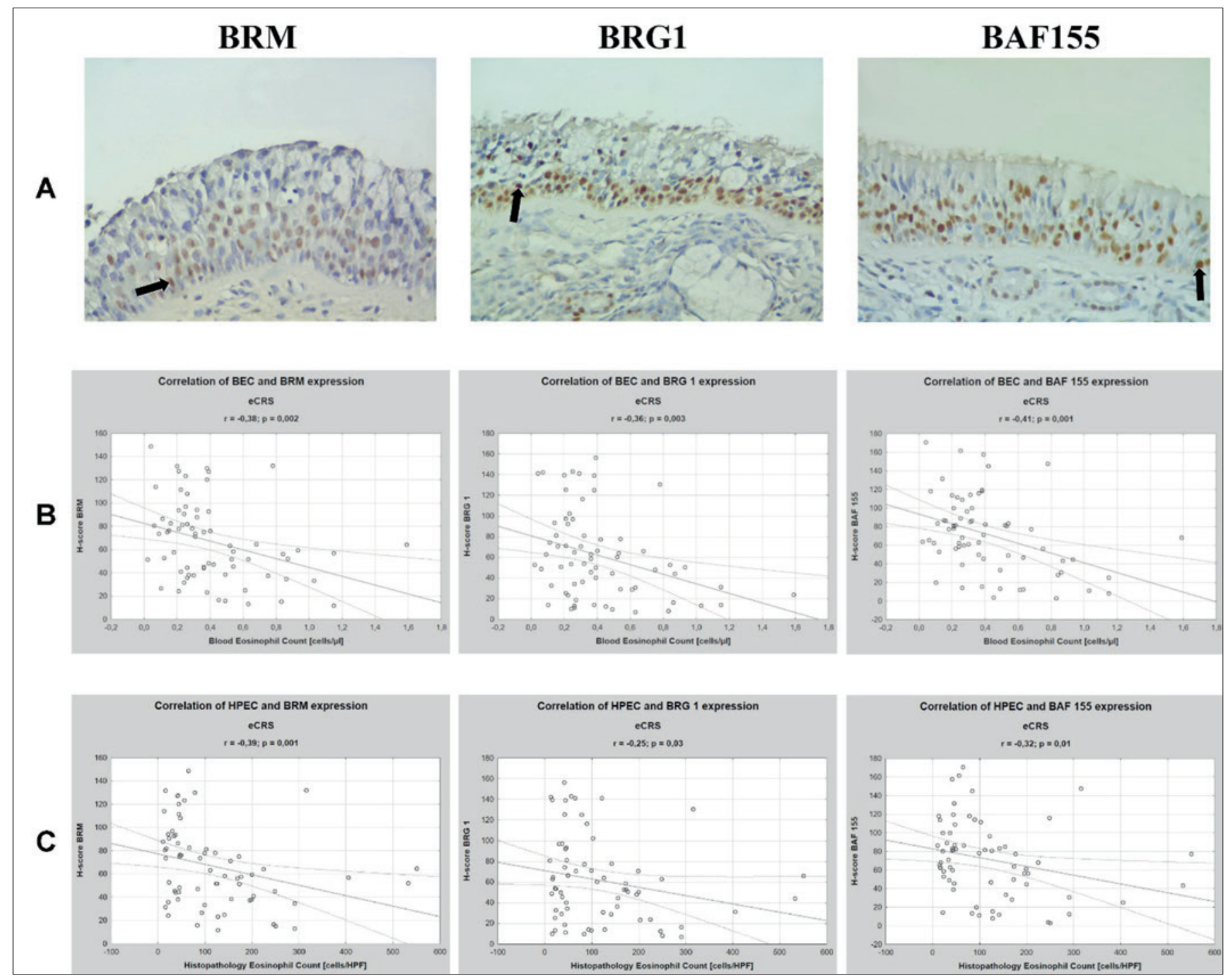

Figure 4. The SWI/SNF complex in patients with eosinophilic chronic rhinosinusitis (eCRS) and correlations with eosinophil counts. (A) Immunostaining (IHC) of sinonasal epithelial cells with BRM, BRG1, and BAF155 antibodies. Antibody dilutions: 1:200 BRM; 1:100 BRG1; 1:200 BAF155. Magnification: 400x. Arrows indicate the nuclei after IHC staining. (B) Correlation between blood eosinophil count (BEC) and H-scores for BRM, BRG1, and BAF155 in eCRS patients. In this group, BEC correlated negatively with SWI/SNF subunit expression levels $(\mathrm{p}<0.05)$. (C) Correlation between histopathology eosinophil count (HPEC) and H-scores for BRM, BRG1, and BAF155 in patients with eCRS. In this group, HPEC correlated negatively with all analysed SWI/SNF subunit expression levels ( $p<0.05)$.

professionals to plan surgical next steps ${ }^{23}$. Bhattacharyya et al. found that Lund-Mackay CT scores correlate with the degree of tissue eosinophilia ${ }^{18}$. Additionally, Kountakis et al. proposed different subtypes of CRS based on CT imaging of the paranasal sinuses and other parameters (nasal endoscopy, HPEC, BEC) ${ }^{24}$. Similarly, Tokunaga et al. used CT scans of the paranasal sinuses, nasal endoscopy results and blood eosinophilia to distinguish eCRS from neCRS ${ }^{25}$. Our study contributes to this burgeoning field by showing the positive correlations between the blood eosinophils count (BEC) and histopathology eosinophilic tissue infiltration (HPEC) with Lund-Mackay CT scores. Patients in the eCRS group who presented with high Lund-Mackay CT scores showed higher HPEC and BEC than patients with low Lund-Mackay scores. Furthermore, we found a significant negative correlation between SWI/SNF expression and Lund-Mackay CT scores. Patients with lower protein expression levels for BRM and BAF 155 presented worse CRS changes in CT scans.

In order to assess CRS severity, sinonasal symptoms are determined using the SNOT-22 scale ${ }^{26}$. Wang et al. noticed that eCRS patients had significantly worse preoperative and postoperative SNOT-22 scores than neCRS patients ${ }^{20}$. Likewise, we found a positive correlation between 

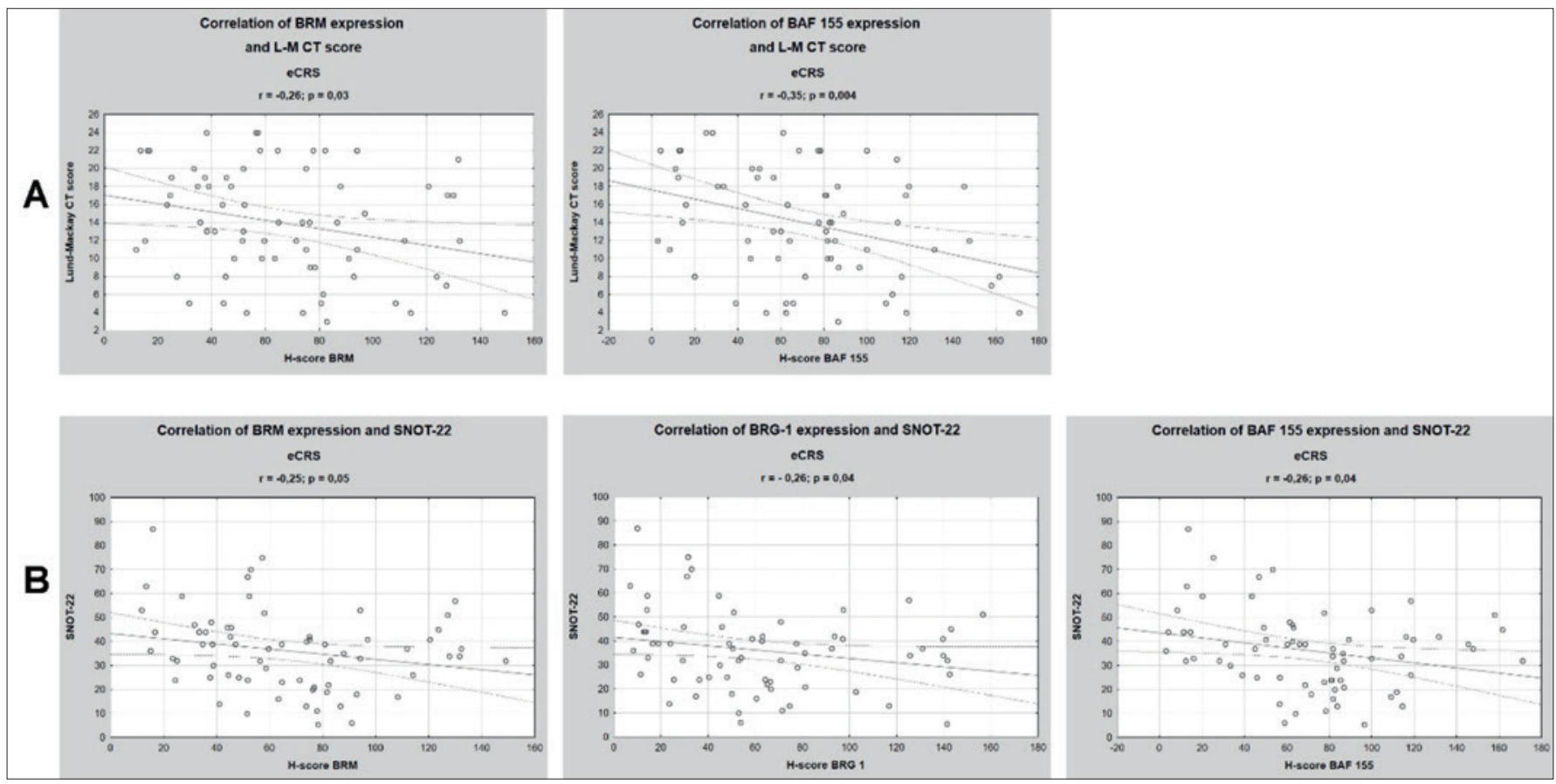

Figure 5. The Spearman correlation for expression of SWI/SNF subunits with SNOT-22 and Lund-Mackay (L-M) CT scores in patients with eosinophilic chronic rhinosinusitis (eCRS). (A) Correlation between H-scores for BRM and BAF155 and L-M CT scores in patients with eCRS. In this group, protein expression levels of SWI/SNF subunits correlated negatively with L-M CT scores $(p<0.05)$. (B) Correlation of H-scores for BRM, BRG, and BAF155 with SNOT-22 in patients with eCRS. In this group, protein expression levels of SWI/SNF subunits correlated negatively with SNOT-22 $(p<0.05)$.

SNOT-22 scores and BEC, as well as a significant negative correlation between expression of the all SWI/SNF subunits and SNOT-22 scores. Due to the fact that the SWI/SNF is involved in infectious diseases and inflammation, patients' quality of life may be affected by SWI/SNF abundance ${ }^{9,22}$. When diagnosing eCRS or neCRS, histopathological examination of the sinonasal tissue and calculation of HPEC are crucial. Some authors have also suggested that BEC is a good parameter because it correlates with tissue infiltration and may be a marker of eCRS ${ }^{24,27-29}$. Ho et al. indicated that BEC was a moderately specific predictor of eCRS, with mean BEC values for eCRS and neCRS patients being $0.42 \pm 0.34 \times 10^{9} / \mathrm{L}$ and $0.17 \pm 0.13 \times 10^{9} / \mathrm{L}$, respectively. They distinguished eCRS based on HPEC ( $>10$ cells/HPF) and proposed a cut-off value for BEC for eCRS patients as $\geq 0.24 \times 10^{9} / \mathrm{L}^{27}$. Like Ho et al. ${ }^{27}$, and according to the EPOS 2020, we established an HPEC cut-off value of $>10$ cells/HPF as a marker for distinguishing eCRS from neCRS. HPEC indicates a specific local eosinophilic infiltration in the paranasal sinuses, while BEC defines systemic eosinophilia, which may be related to allergies, parasites, viruses, bacteria, or even fungus ${ }^{30,31}$. For this reason, we believe HPEC may be a more reliable mean for distinguishing eCRS from neCRS that BEC. Our HPEC cut-off value of $>10$ cells/HPF for eCRS patients influenced the differentiation of CRS patients in favour of eCRS diagnosis (87\% in CRSwNP and 50\% in CRSsNP), and according to our results, the mean BEC for eCRS and neCRS patients was 0.41 cells $/ \mu \mathrm{L}$ and 0.15 cells $/ \mu \mathrm{L}$, respectively. Our results showed high positive correlation BEC and HPEC $(r=0.59$; $\mathrm{p}=0.0001$ ). Our findings contribute to the knowledge that the gold standard for diagnosing of eCRS is histopathological examination of sinonasal tissue and calculation of HPEC. A drawback of this study is the lack of detailed molecular mechanisms explaining how SWI/SNF plays role in the pathophysiology of CRS. However, the study describes potential functional aspects related to the expression of the SWI/SNF in eCRS and resistance to steroids. The strength of our study is that we analysed the clinical aspects of eCRS in relation to its pathophysiology.

\section{Conclusions}

Our study demonstrated that the SWI/SNF subunits are expressed in both eCRS and neCRS and that the SWI/SNF subunits show a strong correlation between blood and tissue eosinophil counts (BEC and HPEC). There is not only molecular but also clinical relevance (Lund-Mackay scoring system, SNOT-22, comorbidities) to these findings. Lower levels of SWI/SNF expression and more eosinophilic infiltration are more advanced clinical symptoms of eCRS. We propose 
that the SWI/SNF complex may play an important role in the pathophysiology of CRS and may be of particular importance in cases of eCRS. The negative correlation of BEC and HPEC with the SWI/SNF subunits may also be a contributor to less successful treatment of eCRS. Patients with the lower SWI/ SNF expression levels may be resistant to steroids and not respond to typical CRS therapy. Finally, the positive correlations between eosinophil counts and clinical findings (LundMackay and SNOT-22 scores) may suggest that there are opportunities to better estimate the severity and prognosis for eCRS patients, as well as treatment response.

\section{References}

1 Fokkens WJ, Lund VJ, Hopkins C, et al. European Position Paper on Rhinosinusitis and Nasal Polyps 2020. Rhinology 2020;58:1-464. https://doi.org/10.4193/Rhin20.600

2 De Corso E, Baroni S, Battista M, et al. Nasal fluid release of eotaxin-3 and eotaxin-2 in persistent sinonasal eosinophilic inflammation. Int Forum Allergy Rhinol 2014;4:617-624. https://doi.org/10.1002/alr.21348

3 De Corso E, Baroni S, Lucidi D, et al. Nasal lavage levels of granulocyte-macrophage colony-stimulating factor and chronic nasal hypereosinophilia. Int Forum Allergy Rhinol 2015;5:557-562. https://doi. org/10.1002/alr.21519

4 Orlandi RR, Kingdom TT, Hwang PH, et al. International Consensus Statement on Allergy and Rhinology: rhinosinusitis. Int Forum Allergy Rhinol 2016;6(Suppl 1):S22-209. https://doi.org/10.1002/alr.21695

5 Brescia G, Zanotti C, Parrino D, et al. Nasal polyposis pathophysiology: endotype and phenotype open issues. Am J Otolaryngol 2018;39:441-444. https://doi.org/10.1016/j.amjoto.2018.03.020

6 Lou H, Zhang N, Bachert C, et al. Highlights of eosinophilic chronic rhinosinusitis with nasal polyps in definition, prognosis, and advancement. Int Forum Allergy Rhinol 2018;8:1218-1225. https://doi. org/10.1002/alr.22214

7 De Corso E, Lucidi D, Battista M, et al. Prognostic value of nasal cytology and clinical factors in nasal polyps development in patients at risk: can the beginning predict the end? Int Forum Allergy Rhinol 2017;7:861-867. https://doi.org/10.1002/alr.21979

8 Kowalik K, Waniewska-Leczycka M, Sarnowska E, et al. Role of chromatin remodeling complex SWI/SNF and VDR in chronic rhinosinusitis. Adv Clin Exp Med 2020;29:313-323. https://doi. org/10.17219/acem/117683

9 Ramirez-Carrozzi VR, Nazarian AA, Li CC, et al. Selective and antagonistic functions of SWI/SNF and Mi-2beta nucleosome remodeling complexes during an inflammatory response. Genes Dev 2006;20:282-296. https://doi.org/10.1101/gad.1383206

10 Trotter KW, King HA, Archer TK. Glucocorticoid receptor transcriptional activation via the BRG1-dependent recruitment of TOP2beta and Ku70/86. Mol Cell Biol 2015;35:2799-2817. https://doi. org/10.1128/mcb.00230-15

11 King HA, Trotter KW, Archer TK. Chromatin remodeling during glucocorticoid receptor regulated transactivation. Biochim Biophys Acta 2012;1819:716-726. https://doi.org/10.1016/j.bbagrm.2012.02.019

12 Wei Z, Yoshihara E, He N, et al. Vitamin D switches BAF complexes to protect beta cells. Cell 2018;173:1135-1149.e15. https://doi. org/10.1016/j.cell.2018.04.013

13 Lund VJ, Mackay IS. Staging in rhinosinusitus. Rhinology 1993;31:183-184.
14 Psaltis AJ, Li G, Vaezeafshar R, et al. Modification of the LundKennedy endoscopic scoring system improves its reliability and correlation with patient-reported outcome measures. Laryngoscope 2014;124:2216-2223. https://doi.org/10.1002/lary.24654

15 Sakalar EG, Muluk NB, Kar M, et al. Aspirin-exacerbated respiratory disease and current treatment modalities. Eur Arch Otorhinolaryngol 2017;274:1291-1300. https://doi.org/10.1007/s00405-016-4273-1

16 Horak F, Doberer D, Eber E, et al. Diagnosis and management of asthma - Statement on the 2015 GINA Guidelines. Wien Klin Wochenschr 2016;128:541-554. https://doi.org/10.1007/s00508-016-1019-4

17 Tomaszewska M, Sarnowska E, Rusetska N, et al. Role of vitamin D and its receptors in the pathophysiology of chronic rhinosinusitis. J Am Coll Nutr 2019;38:108-118. https://doi.org/10.1080/07315724.2 018.1503102

18 Bhattacharyya N, Vyas DK, Fechner FP, et al. Tissue eosinophilia in chronic sinusitis: quantification techniques. Arch Otolaryngol Head Neck Surg 2001;127:1102-1105. https://doi.org/10.1001/archotol.127.9.1102

19 Lang TA, Secic M. How to report statistics in medicine. Philadelphia, USA: American College of Physicians; 2006. p. 490. https://doi. org/10.1136/ebm.12.3.90

20 Wang F, Yang Y, Wu Q, et al. Histopathologic analysis in chronic rhinosinusitis: impact on quality of life outcomes. Am J Otolaryngol 2019;40:423-426. https://doi.org/10.1016/j.amjoto.2019.03.014

21 Jiang N, Kern RC, Altman KW. Histopathological evaluation of chronic rhinosinusitis: a critical review. Am J Rhinol Allergy 2013;27:396402. https://doi.org/10.2500/ajra.2013.27.3916

22 Tartey S, Matsushita K, Vandenbon A, et al. Akirin2 is critical for inducing inflammatory genes by bridging I $\mathrm{KB}-\zeta$ and the SWI/SNF complex. Embo J 2014;33:2332-2348. https://doi.org/10.15252/embj.201488447

23 Hopkins C, Browne JP, Slack R, et al. The Lund-Mackay staging system for chronic rhinosinusitis: how is it used and what does it predict? Otolaryngol Head Neck Surg 2007;137:555-561. https://doi. org/10.1016/j.otohns.2007.02.004

24 Kountakis SE, Arango P, Bradley D, et al. Molecular and cellular staging for the severity of chronic rhinosinusitis. Laryngoscope 2004;114:1895-1905. https://doi.org/10.1097/01. mlg.0000147917.43615.c0

25 Tokunaga T, Sakashita M, Haruna T, et al. Novel scoring system and algorithm for classifying chronic rhinosinusitis: the JESREC Study. Allergy 2015;70:995-1003. https://doi.org/10.1111/all.12644

26 Gallo S, Russo F, Mozzanica F, et al. Prognostic value of the Sinonasal Outcome Test 22 (SNOT-22) in chronic rhinosinusitis. Acta Otorhinolaryngol Ital 2020;40:113-121. https://doi. org/10.14639/0392-100X-N0364

27 Ho J, Hamizan AW, Alvarado R, et al. Systemic predictors of eosinophilic chronic rhinosinusitis. Am J Rhinol Allergy 2018;32:252-257. https://doi.org/10.1177/1945892418779451

28 Sreeparvathi A, Kalyanikuttyamma LK, Kumar M, et al. Significance of blood eosinophil count in patients with chronic rhinosinusitis with nasal polyposis. J Clin Diagn Res 2017;11:MC08-MC11. https://doi. org/10.7860/jcdr/2017/25320.9445

29 Brescia G, Barion U, Zanotti C, et al. The prognostic role of serum eosinophil and basophil levels in sinonasal polyposis. Int Forum Allergy Rhinol 2017;7:261-267. https://doi.org/10.1002/alr.21885.

30 Ravin KA, Loy M. The eosinophil in infection. Clin Rev Allergy Immunol 2016;50:214-227. https://doi.org/10.1007/s12016-015-8525-4

31 Kita H. Eosinophils: multifunctional and distinctive properties. Int Arch Allergy Immunol 2013;161(Suppl 2):3-9. https://doi. org/10.1159/000350662 